\title{
Open Source Tools Covered in Session by Centre for Digital Scholarship
}

Voyant

http://voyant-tools.org

Web-based reading and analysis environment for digital texts. Works with a variety of file types. Produces word clouds, key word in context and word correlations

\section{Google Ngram Viewer}

https://books.google.com/ngrams

Charts the frequencies of any word or short sentence using yearly count of $\mathrm{n}$-grams found in the sources printed between 1500 - present. The Ngram Viewer is optimized for quick inquiries into the usage of small sets of phrases. If you're interested in performing a large scale analysis on the underlying data, download of the corpora is available.

\section{Palladio (Stanford University) http://hdlab.stanford.edu/palladio}

A browser-based tool for managing and presenting data (e.g. .csv, .tab .tsv) in maps, network graphs and image galleries. 


\section{Meshlab}

http://meshlab.sourceforge.net

Open Source 3D model processing, editing and converting software. Meshlab tutorials are available online: https://www.youtube.com/user/MrPMeshLabTutorials\#g/p

SketchFab

https://sketchfab.com/

Publish and find 3D models online

Omeka

https://omeka.org

Open source web publishing platforms for sharing digital collection and creating media-rich online exhibits.

JSTOR Text Analyser

https://www.jstor.org/analyze

Search for related content on Jstor by uploading a document.

\section{Useful Links}

- Centre for Digital Scholarship (UQ) https://web.library.uq.edu.au/locationshours/centre-digital-scholarship.

- Guides available on Text mining and text analysis tools; Data visualisation; Data analysis software; Geographical visualisation systems; 3D Modelling Software

- ANZTLA delegates are welcome to email the Centre cds@library.uq.edu.au for advice on tools for digital scholarship

- The Programming Historian https://programminghistorian.org/ Free, online lessons on digital tools, methods and research processes in digital humanities. 